\title{
NEW DIMENSIONS OF THE POLITICAL COMMUNICATION. CHANCES AND LIMITS
}

\author{
by Teresa Sasińska-Klas
}

Media and communication are subjects which are closely related. For quite some time in each public debate references are made to an increasing dependence between media and communication processes. Explicit attention is paid to a changing context of the communication process, and especially the process of political communication. The role of media in the process of public communication is, on the one hand, quite traditional; that is to inform the public, popularize information and mobilize citizens to action, all in the name of the public good. On the other hand, it is also noticeable that modern media play new roles such as providers of entertainment, scandals, sensation, enjoyment. All this brings a question: which of these functions tell us about the future of the media, and - consequently - how do they change the process of political communication in the public sphere? And is this what we want?

Media - as we see more and more - play a role of open and hidden steersmen of social life. For quite some time we have been noticing decreased frequency in direct relations between people and social interactions between people, while the indirect relations have been growing in importance. In everyday life, we are more and more surrounded by such mediated signs as sounds, radio, commercials, magazine covers, text mes- 
sages, etc. More and more we have been communicating with other people by means of telephones, Internet, we send faxes or emails. These changes are not without influence on the forms of communications between citizens in the private and public sphere. For this reason, we are paying more attention to recognizing the power of media, that is the process of media's influence on civic culture, people's behavior, the decision-making process and its results.

We also notice lack of media's influence, that is their powerlessness. This is the case, for example, in the area of popularizing the legal culture among citizens. Out of all political campaigns that are organized, many have ended with a failure, and after this failure the citizens have not been better informed or convinced and motivated to undertake planned actions in a given area of social life. Many political leaders have been disappointed with the media and their credibility, especially in crisis situations when they were expecting the media to become the allies of the government. And nothing like this happened.

When we analyze the role of the media in the directed against the government social protests which took place in the countries of Northern Africa in the winter and spring of 2011, we notice that the political leaders in Tunisia, Egypt, Morocco, Libya and other countries of the region, who for many years had fully controlled the media, especially electronic media (that is television and radio), have not been able to control the social revolts or are struggling to control the tumbling political system and its steersmen. However, it seems that the fall of dictatorships in this part of the world is only a matter of time. What failed here in the communication process between the government and the citizens?

It is impossible to show only one reason for this situation. As always there are numerous explanation to these phenomena. It is important to point out that social ties, which to a greater degree are - in the modern world - generated by the media, are becoming more anonymous and oneway. These indirect relations, which are growing in importance, are virtual. They do not have such forceful potential as direct ties, face to face contacts. The effectiveness of the media is decided, above all, by direct relations and how favorable and how unfavorable they are to indirect relations, those of the media. 
Hence, arises a question, which requires an answer how today's governments should effectively communicate with citizens, what and whose interests are vested in the media, and in which directions should the changes go in political communication in the oncoming few years, especially when considering new, emerging context.

In all political cultures we observe the process of strengthening the political role of the media, and what is related to it, an increase in importance of the process of political communication as generated by mass media. What does this change mean and what does it translate into? In the last decades media, in the technological sense, have been changing very dynamically. This process is still in growing phase. These changes relate to both media technologies (such as printing, television and radio) as well as media institutions and their form of work in public sphere (changes in the work of journalists in radio and tv stations, in Internet editions of information providers who often use the slogan "Whole truth, 24h/day").

From a point of view of democracy the ongoing changes in the media and the observed within them process of public communication as a force favoring political emancipation, more inclusive, participatory and democratic way of communication. This is a positive assessment of the results of technological changes in the media. In this case, the role of the so-called social media is particularly stressed as those contributing to the decentralization of power, which, further, contributes to an increased influence of the citizens in the area of exchanging information, opinion, ideas. Blogs, chat rooms, social networking services, discussion forums are of particular influence here.

A different perspective on the changes within media, and - as a consequence in the transformation of the political communication process - is the perception that media are a tool of domination used for cementing the existing social order. New communication technologies enlarge this sphere of dominance as they create new opportunities to influence citizens. Media institutions are being developed and their position in the public sphere is visibly increasing. It is being pointed out that more and more media are aspiring to the position of the "first" power, meaning they govern, or at least have significant influence on, public institutions and 
citizens. The process of political communication is directly related to this type of changes in the media and reveals one more type of dependence, namely an economic dependence of journalists, the steersmen of the media, from media owners, and indirectly from the class which controls the capital. An assessment of this direction of changes and relations between the media and the communication process in the public sphere is a critical one.

Another perspective points to neutrality of information technologies, which for this reason can serve both hegemonic and association communication. It is being stressed that from this perspective media are politically neutral. Some point out that they are a-political. And for this reason, the media can strengthen the position of the government, influence it, which means they can change the ways of its functioning.

An elitist approach, on the other hand, underlines the complexity of information technologies, which causes that access to technologies, as well as the opportunity to use their potential, is limited to a small group of people, usually those who are educated, work in public administration, are part of management teams, or are politicians. It allows these groups to make many decisions which are important for wider society. At the same time, the remaining part of the society, the mass, remains under the influence of decisions made by the selected minority and has an illusionary impression that they can influence real choices and decisions made in public sphere. Here, the political role of the media, together with adjusted for this purpose the process of political communication, is assessed quite ambivalently.

This indicates the gratifications and threats resulting from the functioning of this mechanism of dependence and eligibility. Hence, the political capabilities of media's influence are becoming more and more multidimensional. Nonetheless, what should be paid attention to is the context within which the modern media function and which is undergoing a dynamic change. Analysts of the communication process, especially the creators of the concept of agenda-setting, point out that the media (press, radio and television) are more effective in shaping the range and hierarchy of issues which people discuss and think about than influence what people think about these issues. 
Since the 1922 publication of the Walter Lippmann Pubic Opinion it has been stressed that the role of media in the process of shaping public opinion is increasing growing. On the other hand, we can notice, in parallel, some actions undertaken by governments which aim at controlling the media. The most prominent example is the Patriot Act passed by the US Congress in 2001 in order to protect the citizens against terrorism but which, at the same time, was a document allowing government agencies to deeply enter the private lives of citizens. Today, we notice a visible asymmetry between the range of private sphere (which is shrinking) and the public sphere (the range of which is broadening). This trend is being strengthened by new media, such as the Internet, social networks, which very dynamically broaden the range of public sphere, a debate within it, at the cost of private sphere. A perfect example was the 2008 presidential campaign in the USA which will be shown as an inauguration of new forms of political communication with all effects it had on this process.

\section{THE MEANING OF NEW MEDIA IN THE PROCESS OF POLITICAL COMMUNICATION}

Recently we are more and more broadly using the term "new media". But what does this term really mean? New media is a term used to describe digital and computerized communication technologies which developed in the late 1990s. Experiences of the last few years in the area of using new media in the process of political communication show that they are becoming an integrated element of this process and their usage in the oncoming years will only become bigger.

Observing changes in the process of political communication, which are currently taking place and which result from the influence of new media, we should refer to the roots of the concept of the public sphere as put forward in mid-1970s by a German philosopher Jurgen Habermas. Habermas suggests that public sphere should be regarded as a place where the members of a community are able to collectively formulate opinions in an area which is deprived of the influence of the government and eco- 
nomic entities ${ }^{1}$. This concept also stresses a necessity of the citizens to actively participate in the process of communication and not to be only passive recipients of messages coming "from above", from the government and the media. A regular contact between citizens and their political representatives in political institutions allows a realization of Abraham Lincoln's ideal of democracy as the government of the people, by the people and for the people².

According to Habermas an interactive nature oh the new media is the first chance for the realization of the modern public sphere. One of the main strengths of the new media in the context of political communication is a possibility to receive „first hand" information. What does it mean? This is an opportunity to obtain from the source, the information about important events, which are taking place at a given moment, as well information on the election program, the calendar of the work of a political party or any other public organization. An interested citizen can check the internet page of a given institution and find what he/she is looking for.

Research conducted by Paul Haridakis from Kate State University on the sources of information about important facts and events show that average American citizens prefer to search information on important events in less official sources, that is from independent blogs or social networking sites, than read about them on information sites prepared by traditional media ${ }^{3}$. Already in the 2004 presidential campaign in the USA, the Democratic candidate Howard Dean drew attention to the potential of new media in the process of building social dialogue, which before was limited to public opinion polls.

Entering into the market of the new media has significantly changed the course and meaning of the existing mechanisms. New media offer in the public sphere an equal dialogue between political actors and the citizens. This dialogue between the political actors and citizens can be shortterm, occasional, or long-term, more permanent. It allows the citizens,

1 J. Habermas, The public sphere, (1974) [in:] The information society, New York 2004, pp. 350-353.

2 Ibidem, pp. 350-353.

3 See: Social media and presidential election: Scientists examine impact of You Tuber and My Space, http://www.physorg.com/new144674921.html. 
those who are "on the bottom" to lead their own campaigns and all kinds of protest and contestation activities. Opinions of the users of new media are just as important as the opinions of those who participate in the election meetings. Noticeable is an increased number of online debates during which a confrontation between politicians and citizens takes place. In this way, a new quality of public sphere is being shaped, in which the new media have an increasingly growing role.

\section{ORGANIZATION OF POLITICAL SUPPORT USING THE NEW MEDIA}

Analyzing the experience of the 2008 presidential campaign in the USA one cannot but point to a significant application of Internet as a means of communication with voters. This was a result of a specifics of this medium, which allows precise addressing of the message to a specific target group ${ }^{4}$ The mere presence of a candidate, a party or an institution in the net does not yet guarantee this success. One needs to know beforehand in which way the voters can be drawn to a candidate and what to do to make this group support a particular candidate.

Campaign managers of the residential campaign Barack Obama presented its messages not only through a traditionally organized campaign, but also in the net, to precisely selected target groups. The method which brought planned results was obtaining funds for the online campaign in a form of collecting, in a database, information about voters. This information allowed to more precisely select and position messages for adequate groups of potential voters.

Data which was freely delivered by the Internet users to campaign managers, allowed to obtain more detailed information about Barack Obama's supporters. What can be established in such a situation? First that place of living of a person as well as the form of property owned

\footnotetext{
4 See K. Winnipeg, B. Hardy, K. Jamieson, Did citizens' preferences for online sources for campaign information impact learning during the 2008 U.S. general election? - paper presented at the APSA 2010 Annual Meeting, http://ssrn.com/abstract=1644654.
} 
(house, apartment), religious background, size of family, credit obligations, sources of obtaining information (local television, radio, press or the Internet), at what time of the day the potential voter checks his/her email account and answers messages.

Data which the users themselves, on their own free will, presented to the Democratic party staff permitted a search for more specific information about those people who support Barack Obama5. Using such welldeveloped database specialists in political communication working for Obama's campaign, could direct to the recipient of their messages contents which were corresponding to the characteristics of the respondents themselves. In this way a potential voter could hear and see what he/she was most interested in and which was the closest to his/her interests and values. Such mechanism allowed for a more precise targeting of potential voters. Analyzing the characteristics of the election campaign of Barack Obama from the perspective of the effectiveness of the process of political communication, one needs to point out that apart from the Internet it was focused on search marketing and contextual (?) commercials. Most often used search engines were Google and Yahoo. Contextual commercials and their usage in political campaigns means that this is a commercial automatically adjustable to the content that is being emitted ${ }^{6}$. It includes key words and their application allows in any material to display, in parallel, promotional materials of similar nature, which builds a kind of "thematic family" and draws a potential voter to the topic covered during the campaign. It is believed that a person who will pay attention to such a commercial will react to it positively, especially when its content is related to information which is being sought after by this person. And this reaction is more positive than in situations when information is not of interest to a reader.

On the shaping of a positive image of Barack Obama a great influence had a new element of communication, that is social networks. These networks actively joined the process of creating the image of the candidate.

5 M. Madden, Barack Obama's super marketing machine, 2008, http://www.salon. com/news/feature/2008/07/16/obama.

6 B. Dwornik, Report on Content Advertising in Poland, 2008, www.money.pl. 
They included: Facebook, MySpace, YouTube, Flickr, Digg, Twister, Eventful, Linkedin, Black Planet, Faithbase, Eons, Glee, MiGente, MyBatanga, AssianAve, DNC Party Builder'. Campaign managers planned to use these networks mainly to reach out to young people to whom they wanted to give an unlimited opportunity to discuss and comment broadcast material. The purpose was to increase, by means of this medium, an interest in the oncoming elections and mobilize young people to action. Statistical data illustrating the number of registered users and the number of visits on these sites show that the most effective in building a virtual community around Obama was Facebook. We cannot go that far to say that Obama won thanks to new media, and especially social networks, but without a doubt these sites have contributed promote such actions as: Fight the Smears. On Facebook, Obama was supported by 2,5 million users while the support for his opponent was only around 632 thousands of Internet users 8 . McCain's campaign managers were building a virtual community around their candidate within a specially prepared portal called McCain Space.

New media and Digital democracy experts point that what draws special attention in the process of political communication in the last presidential campaign in the USA is a change in direction in the flow of information' ${ }^{9}$. In traditional media and campaigns organized with their application the communication process follows the "top-down" approach. In the 2008 campaign the "bottom-up" model was more applied, which was created by the citizens themselves. For example, YouTube was not only used by the presidential candidate and his campaign managers but also by the media. This was most visible during the presidential debate organized by the television network CNN, which by means of YouTube, mobilized over 2 thousand users to record and publish questions to a candidate.

\footnotetext{
7 See Obama everywhere, www.barackobama.com.

$8 \mathrm{http}: / /$ techpresident.com/scrape_plot/facebook/2008.

9 Lecture given by Prof. David Silver from the University of San Francisco entitled. Digital Democracy, 24.03.2009r. at the Institute of Journalism and Social Communication, Jagiellonian University, Cracow.
} 
In previous election campaigns the sender (campaign managers) was trying to control all messages directed to recipients. In 2008 this has changed. Specialists in political communication in Obama's campaign decided to take a different step. They decided not to use only one, created for the campaign, message, but to multiply this message and include in its creation potential voters. Campaigners were encouraging Obama's supporters to load their own clips to YouTube. One of the first materials broadcast on YouTube was a music clip "Yes We Can" which was prepared by musicians William from Black Eyed Peas and Jesse Dylan. This clip was very popular throughout the entire campaign and was viewed up to half a million times per day. In this clip, the artists performed a music version of famous speech by B. Obama in which, relating to solving the economic crisis, he used the phrase: "Yes, We Can".

Another method to use new media in the election campaign was related to mobile phones and their communication potential, which is significantly different from fixed-lines. Obama promoted himself as a fan of new communication technologies, the proof of which was his constant use of the BlackBerry. Campaign managers decided to provide the Internet users with free applications and ringtones. Hence, actions were taken towards constant flow of information to citizens about all events that were related to the campaign. Television broadcasts and internet sites included a short message Text Hope.62262". It encouraged the users to send short text messages to Obama campaign. Each new piece of information was registered to allow for feedback.

One in sixths of Obama's voters actively supported him in the net ${ }^{10}$. On November $4^{\text {th }} 2008,69$ million of American citizens voted for Barack Obama. Out of them 11,5 million were internet users who actively supported his candidacy during the campaign. These were not only young people, but also the elderly, who, in many cases, set up the Internet to send a contribution to his campaign.

\footnotetext{
10 Data presented by Barack Obama's Campaign Director for the New Media - Joe Rospars in the meeting at the US Consulate in Cracow on 21.03.2009.
} 
Also worth noticing is that during this campaign a great number of local networks of volunteers emerged who actively joined the campaign. The Internet served as a channel of communication and sending information between different groups, which, in a short period of time created a certain social movement. The campaign reached to the grassroots level, that is the lowest level of inter-human communication, usually performed in an indirect form, by means of the Internet and short text messages.

The above presented data show that Obama's campaign on the Internet has brought a change not only in the form of the candidate's election slogan Change, but also in the citizens' thinking about themselves and about the ways to communicate between each other at the times which are as important for the citizens as the elections of the president are.

It was enough for one person (the so-called access point) who is connected to the Internet to become a link between the Obama campaign and the offline community. This allowed the grassroots activities to take off even among senior citizens and in areas where access to the Internet is still limited. This is the new dimension and new quality in the process of political communication.

Additionally, on the Barack Obama's campaign website and additional service called My.BarackObama (slightly later the McCain campaign created a service called McCain Space), which allowed the supporters of both candidates to maintain relations during the campaign. This allowed the supporters of both candidates to exchange ideas for actions, which could help their candidate. The same professional tools which until that time had only been used members of the campaign for the organization of political events, were now offered to volunteers who could, in their neighborhoods, in their areas, in their states, organize an event promoting a candidate to increase his chance to win the election. Obama's supporters, who were very active on the Internet, organized over 200 thousand events offline ${ }^{11}$, which - without a doubt - contributed to the success of their candidate in the general election. Trust which the campaign managers

\footnotetext{
11 Data presented by Joe Raspars.
} 
gave to the volunteers caused that they felt like real participants in the election process, the authors and actors of the change.

The strategy to engage in the election campaign local communities by offering them tools and ad dressing them in the following way: Go and vote. Tell your friends to vote dramatically changed the way of communication between campaign managers, the candidate and the voters ${ }^{12}$ and by its personalization turned out to be particularly effective.

\section{FINAL REMARKS}

The 2008 election campaign in the USA has proved highly innovative in terms of using the Internet in the process of political communication. And this should be positively assessed. One could assume that in the future political campaigns will be run with the help of a greater number of Internet tools, which depends on further expansion of this medium and education on using new media in the process of political communication. This will undoubtedly lead to an increase in campaign budgets and will draw more attention to selecting adequate tools for specific target groups among the Internet users.

One can also assume that the role of the television debates, as used

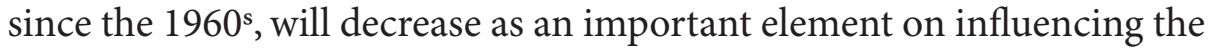
citizens on their election choices. This, one can assume, will change towards a move of communication into social network sites. The experience of the 2008 campaign shows that the traditional media have decreased their usefulness in the campaigns and that they were put on a side for the sake of an increasing role of the Internet by means of which campaign managers were able to shaper their own messages.

The Internet has led to a change in the model of communication during election campaigns. It has increased the importance of messages formulated from the bottom, which contributed to an increased civic activity. This leads to positive conclusions on using new media in the process of

\footnotetext{
12 Opinion presented by David Silver, see endnote 9.
} 
political communication. Nonetheless, it should also be taken into consideration that new media have not entirely pushed out the old media and that it probably will not happen in the future. The new media have overlapped the old media and caused that the campaign online is parallel to the traditional campaign. And this is what constitutes a deep quality change in the process of political communication, in which the role of new media is visibly increasing. 